\title{
Mass spectrometry as a tool for identifying group D2 corynebacteria by their fatty acid profiles
}

\author{
F. Couderc, ${ }^{1}$ D. De Briel ${ }^{2}$ N. Demont, ${ }^{1}$ V. Gilard ${ }^{1}$ and J. C. Promé ${ }^{1 *}$ \\ ${ }^{1}$ Centre de Recherche de Biochimie et de Génétique Cellulaire du CNRS, 31062 Toulouse Cedex, France \\ ${ }^{2}$ Institut de Bactériologie, Université Louis Pasteur, 67000 Strasbourg, France
}

(Received 17 January 1991; revised 20 April 1991; accepted 9 May 1991)

\begin{abstract}
Corynebacterium group D2 (CGD2) are lipophilic antibiotic-multiresistant bacteria involved in some infections of immunocompromised patients. The fatty acid composition and structure of different strains was established by several mass spectrometric methods, particularly negative ion tandem mass spectrometry coupled with capillary gas chromatography. Non-hydroxylated fatty acid profiles of three strains of CGD2 (ATCC 43042, ATCC 43043, ATCC 43044) were almost identical and revealed the presence of several straight chain unsaturated fatty acids from the $\omega-9$ series, with even carbon numbers ranging from 14 to 24 . Branched saturated fatty acids were mainly anteiso-heptadecanoic acid and tuberculostearic acid. Surprisingly, a relatively large quantity of 10-methylene octadecanoic acid was found. The non-hydroxylated fatty acid profile of one rare $\beta$-lactam susceptible strain (SC1) was different; 10-methylene octadecanoic acid was lacking whereas tuberculostearic acid was much more abundant. In contrast, the four CGD2 strains displayed highly similar mycolic acid patterns. The major mycolic acid species corresponded to $\mathrm{C} 32, \mathrm{C} 30$ and $\mathrm{C} 28$ bis-unsaturated with a double bond on each branch at the $\omega-9$ position. The comparison of the mycolic acid composition and structure with those of other medically important corynebacteria strains, revealed a characteristic pattern for CGD2 strains, and CGD2 strains were easily distinguished from Corynebacterium jeikeium (CIP 82.51).
\end{abstract}

\section{Introduction}

The analysis of total cellular fatty acid composition has proved useful for the classification and identification of bacteria (Minnikin \& Goodfellow, 1980; Daffé et al., 1983; Athalye et al., 1984), particularly for coryneform and related taxa (Jones \& Collins, 1986). The structures of mycolic acids, together with the nature of branched and straight chain fatty acids, have been used for taxonomic studies (Corina \& Sesardic, 1980; Minnikin \& Goodfellow, 1980; Collins et al., 1982; Suzuki \& Komagata, 1983). The position of double bonds in unsaturated fatty acids also has taxonomic significance (Suzuki et al., 1982).

Corynebacterium group D2 (CGD2) (King, 1972) are lipophilic antibiotic-multiresistant bacteria. They are potential pathogens in immunocompromised patients and have been involved in urinary tract infections (Soriano et al., 1988; Soriano \& Fernandez-Roblas, 1988; De Briel et al., 1991) and in one case of endocarditis (Langs et al., 1988). Although the GC profile of the fatty acids from CGD2 has been presented already (Soriano $e t$ $a l .$, 1988), together with their mycolic acid composition
(Herrera-Alcaraz et al., 1990), several components remained undetermined. The work described in this paper used a new mass spectrometry approach (Savagnac et al., 1989), allowing the precise characterization of several unknown components. Furthermore, the mycolic acid profile was shown to differ from that already described. However, a comparison with other coryneform bacteria grown in the same conditions, showed a characteristic mycolic acid pattern for CGD2.

\section{Methods}

Strain cultures. The following strains were obtained from the American Type Culture Collection (ATCC), Rockville, MD, USA, the National Collection of Type Cultures (NCTC), London, UK, and the Collection of the Institut Pasteur (CIP), Paris, France: Corynebacterium group D2 ATCC 43042, ATCC 43043, ATCC 43044, C. pilosum ATCC 29592 (type strain), C. xerosis ATCC 373 (type strain), C. bovis NCTC 3324 (type strain), C. minutissimum NCTC 10288 (type strain), C. diphtheriae CIP 78.02, C. jeikeium (C. group JK) CIP 82.51, C. mycetoides CIP 55.51 (type strain), C. pseudotuberculosis CIP 52.97, $C$. renale CIP 69.37. The rare $\beta$-lactam-susceptible strain of Corynebacterium D2 (strain SC1) was isolated as previously reported (De Briel et al., 1991). 
All bacteria were grown on $5 \%(\mathrm{v} / \mathrm{v})$ sheep blood agar (trypticase soy agar, BioMérieux, France) supplemented with Tween $80(1 \%, \mathrm{v} / \mathrm{v}$; Merck, FRG) and incubated at $37^{\circ} \mathrm{C}$ for $72 \mathrm{~h}$. This medium was derived from a selective-enrichment medium (De Briel et al., 1991). Cultures were checked for purity.

Isolation and separation of fatty acids. Cells ( $300 \mathrm{mg}$ wet wt) were harvested using a wire loop, and were hydrolysed using $2 \mathrm{ml} 25 \%$ (w/v) $\mathrm{KOH} / 50 \%$ (v/v) ethanol overnight at $85^{\circ} \mathrm{C}$. The mixture was then extracted with $2 \mathrm{ml}$ chloroform after acidification with $1.5 \mathrm{ml} 6 \mathrm{M}$ $\mathrm{HCl}$. The chloroform layer was evaporated to dryness and hydrolysed again using $2 \mathrm{ml} 5 \%(\mathrm{w} / \mathrm{v}) \mathrm{KOH}$ in $50 \%(\mathrm{v} / \mathrm{v})$ methanol to remove ethyl esters formed during the first hydrolysis. The free acids were methylated with diazomethane by addition of a few drops of an ethereal solution of diazomethane until the yellow colour remained. Excess reagent was destroyed with a dilute solution of acetic acid in diethyl ether.

Non-hydroxylated fatty acid esters and mycolic acid esters were separated on a silicic acid HPLC column (nucleosil-50, $5 \mu \mathrm{m}$, $100 \times 4-6 \mathrm{~mm}$, SFCC, France) using a 95:5 cyclohexane/ethyl acetate solvent mixture. Trimethylsilyl (TMS) ether derivatives were synthesized by dissolving approximately $0.1 \mathrm{mg}$ methyl mycolate in $0.5 \mathrm{ml}$ bis-silyltrifluoroacetamide (BSTFA) containing $0 \cdot 1 \%$ trimethylchlorosilane (TMCS). The reaction was complete after $3 \mathrm{~h}$ at room temperature. Pentafluorobenzyl (PFB) derivatives were synthesized by mixing approximately $1 \mathrm{mg}$ free fatty acids with pentafluorobenzylbromide $(2 \mu \mathrm{l})$, diisopropylethylamine $(2 \mu \mathrm{l})$, acetonitrile $(50 \mathrm{ml})$ and methanol $(10 \mu \mathrm{l})$. The mixture was stirred at room temperature for $1 \mathrm{~h}$ (Promé et al., 1987).

Mass spectrometry. Mass spectrometry was performed on a reverse geometry BE mass spectrometer (ZAB-HS, VG Analytical, Manchester, UK) fitted with a combined electron impact/chemical ionization $(\mathrm{EI} / \mathrm{CI})$ ion source. The accelerating voltage was $8 \mathrm{kV}$.

Gas liquid chromatography coupled with electron impact mass spectrometry. The mass spectrometer was interfaced with a DANI 3800 gas chromatograph. An aluminium-sheathed fused silica column $(0.33 \mathrm{~mm}$ i.d., $12 \mathrm{~m}$ length, coated with $0 \cdot 1 \mu \mathrm{m}$ HT5 phase, SGE, Ringwood, Victoria, Australia) was used for separations. The gas chromatographic system was connected to the ion source through a polyimide-sheathed deactivated fused silica column $(0.05 \mathrm{~mm}$ i.d., $20 \mathrm{~cm}$ length) to ensure electrical insulation. This interface was heated at $270^{\circ} \mathrm{C}$, and helium was the carrier gas. The mass scan speed was $0.8 \mathrm{~s}$ per decade, and the injection was carried out using a Ross injector.

Non-hydroxylated fatty acid methyl esters were analysed directly (oven temperature rising from 80 to $250^{\circ} \mathrm{C}$ at $2{ }^{\circ} \mathrm{C} \mathrm{min}-1$ ). The injector temperature was $250^{\circ} \mathrm{C}$.

Mycolic acid esters were first converted into their O-TMS ether derivatives as described above, and were then injected at $270^{\circ} \mathrm{C}$ (oven temperature rising from 140 to $350^{\circ} \mathrm{C}$ at $2{ }^{\circ} \mathrm{C} \min ^{-1}$ ).

Electron-capture negative ion tandem mass spectrometry. The PFB esters of the non-hydroxylated fatty acids were characterized by combined capillary GC-tandem mass spectrometry (GC/MS/MS) working in the negative ion mode. The $\mathrm{CI}$ source was filled with methane, and a $70 \mathrm{eV}$ electron beam was used. The mass spectrum of each PFB ester was very simple, since it only exhibited the carboxylate ion. A preliminary GC/MS experiment was carried out to determine both the molecular mass of each carboxylate anion and the retention time of the corresponding PFB.

In a second experiment, the collision cell located between the magnet and the electrostatic analyser was filled with helium. The magnet was set to transmit the carboxylate anion of each species, which appeared at the expected retention time. The electric voltage was scanned repetitively at a speed of $1.5 \mathrm{~s}$ per cycle, and all spectra were collected and stored. The kinetic energy spectra were converted into mass spectra by computer calculation (Courcelle et al., 1989).

PFB esters of corynomycolic acids were analysed in a similar way, except that the direct inlet probe was used. Each carboxylate anion was successively focused on the gas cell, by adjusting the magnet to the appropriate field while scanning the electrostatic voltage.

\section{Results}

\section{The negative ion $G C / M S / M S$ method}

Negative ion electron-capture ionization of fatty acid PFB esters dissociated them into the corresponding carboxylate anions and the PFB radical (Reaction 1).

\section{Reaction 1

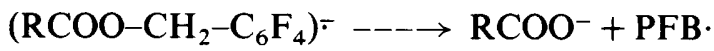

Upon collision activation, the carboxylate anions were cleaved at each carbon-carbon bond by a charge-remote fragmentation process, the charge remaining on the carboxylate moiety (Tomer et al., 1983; Adams, 1990). Since vinylic and double bonds were fragmented more slowly than other bonds, a double bond could be located by three consecutive weak peaks surrounded by two intense ones, due to faster cleavage of allylic bonds. A methyl branch was located by the absence of a single peak in the sequence of regularly spaced ones. Fatty acids containing both double bonds and alkyl branches were easily characterized, which is relatively difficult using other mass spectrometric methods. This method was greatly improved by direct coupling with capillary GLC, which allowed the molecular separation of almost all the fatty acid isomers (Promé et al., 1987, 1990; Couderc et al., 1989a).

\section{Profile and structure of the non-hydroxylated fatty acids of $C G D 2$}

Palmitic acid is the major straight chain saturated fatty acid of CGD2 (Fig. 1). Small amounts of tetradecanoic, pentadecanoic, heptadecanoic, stearic and tetraeicosanoic acids were also detected. Branched saturated fatty acids were identified as tuberculostearic acid (Fig. $2 b$ ) and anteiso-heptadecanoic acid (Fig. 2a), together with small amounts of iso-fatty acids.

Straight chain unsaturated fatty acids of the $\omega-9$ series were identified, namely $\Delta 5$-tetradecenoic, $\Delta 7$-hexadecenoic, $\Delta 9$-octadecenoic, $\Delta 11$-eicosenoic and $\Delta 15$ - 


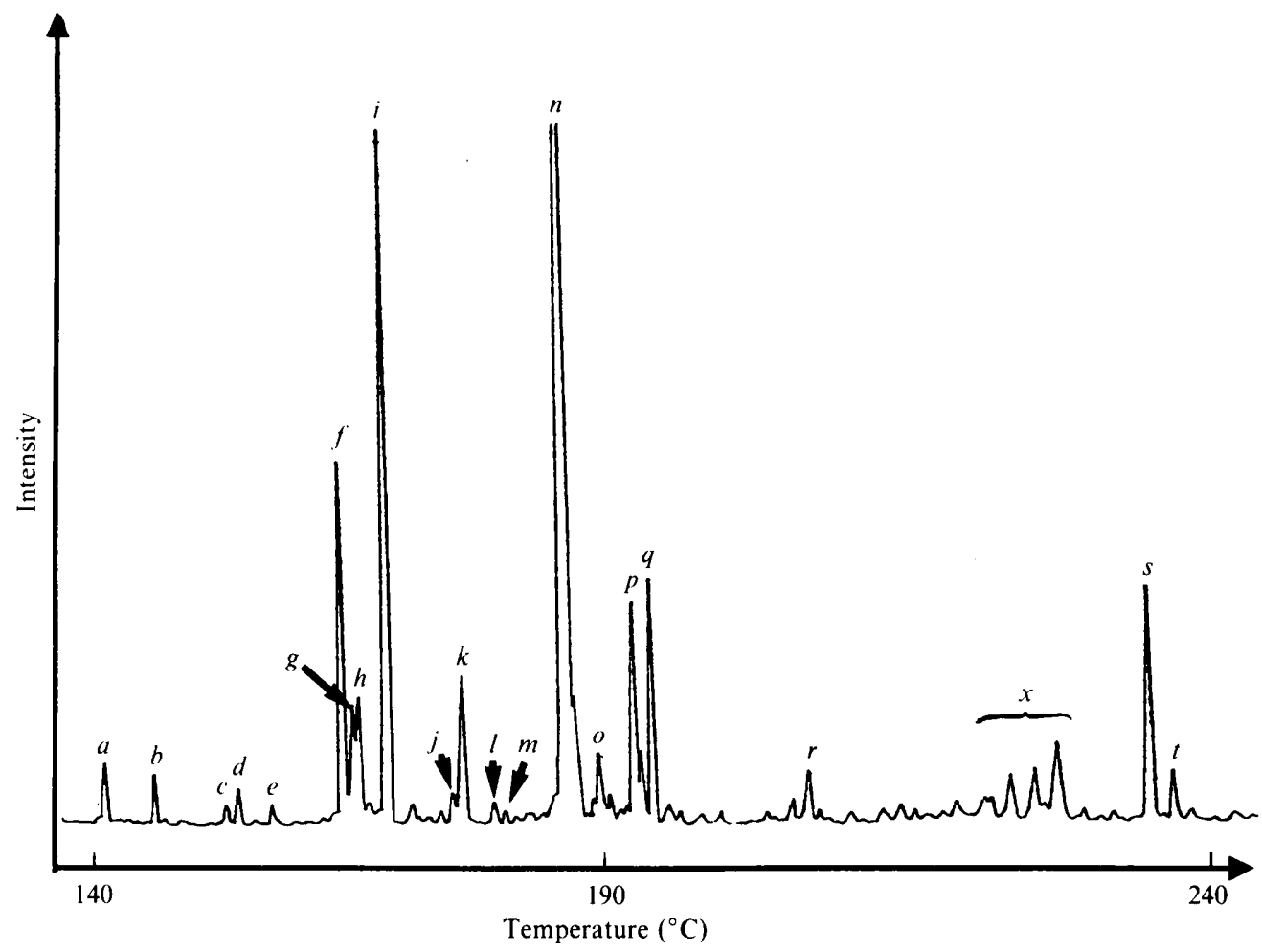

Fig. 1. GC of PFB ester derivatives of the non-hydroxylated fatty acids from Corynebacterium D2, strain ATCC 43043. For abbreviations of the fatty acid nomenclature, see legend to Table 1 . Identification: $(a) \mathrm{C} 14: 1 \Delta 5 ;(b) \mathrm{C} 14: 0 ;(c) \mathrm{C} 15: 0 \mathrm{i} ;(d) \mathrm{C} 15: 0 \mathrm{a} ;(e)$ $\mathrm{C} 15: 0 \mathrm{n} ;(f) \mathrm{C} 16: 1 \Delta 7 ;(g) \mathrm{C} 16: 1 \Delta 9 ;(h) \mathrm{C} 16: 1 \Delta 11 ;(i) \mathrm{C} 16: 0 \mathrm{n} ;(j) \mathrm{Cl} 7: 0 \mathrm{i} ;(k) \mathrm{C} 17: 0 \mathrm{a} ;(l) \mathrm{C} 17: 1 \Delta_{8}^{\mathrm{R}} ;(m) \mathrm{C} 17: 0 \mathrm{n} ;(n) \mathrm{C} 18: 1 \Delta 9 ;$ (o) $\mathrm{C} 18: 0 \mathrm{n} ;(p) \mathrm{C} 19: 0 \mathrm{R}_{10} ;(q) \mathrm{C} 19: 1 \Delta^{\mathrm{R}}{ }_{10} ;(r) \mathrm{C} 20: 1 \Delta 11 ;(s) \mathrm{C} 24: 1 \Delta 15 ;(t) \mathrm{C} 24: 0 \mathrm{n} ;(x)$ non-fatty acids.

tetracosenoic acids (Fig. $2 d$ ). Surprisingly, a relatively large quantity of 10 -methylene octadecanoic acid was found (Fig. 2c). This peculiar structure was clearly deduced from the pattern between the two abundant ions at $m / z 195$ and $m / z 141$ (allylic cleavages) where the middle weak signal was lacking (Couderc et al., 1989b). This methylene-branched fatty acid is an intermediate in tuberculostearic acid biosynthesis (Lenfant et al., 1966; Akamatsu \& Law, 1970). Only minute amounts have been detected in Mycobacterium (Promé et al., 1990) and it has not been previously reported in lipids of Corynebacterium.

Three strains of CGD2 (ATCC 43042, ATCC 43043, ATCC 43044) exhibited similar fatty acid profiles (Table 1). The only difference was quantitative; the abundance of both tuberculostearic acid and 10-methylene octadecanoic acid was lower in strain ATCC 43042 than in strains ATCC 43043 and ATCC 43044. The SC1 strain gave a different profile: 10-methylene octadecanoic acid was not detected and tuberculostearic acid was found to be two to ten times more abundant than in the other strains. Thus, although three strains of CGD2 exhibited a characteristic non-hydroxylated fatty acid profile, the fourth strain had a similar profile to several other corynebacteria and could not be differentiated in this way.
Table 1. Fatty acid composition of four different strains of $C G D 2$

$i$, iso type; a, anteiso type; $n$, linear type; $R_{j}$, methyl branched; and $\Delta^{\mathbf{R}}{ }_{j}$, methylene branched on carbon number $j$. Percentages correspond to the relative area of the peaks using a flame ionization detector

\begin{tabular}{|c|c|c|c|c|}
\hline Fatty acid & $\begin{array}{c}\text { CGD2 } \\
\text { ATCC } 43042 \\
(\%)\end{array}$ & $\begin{array}{c}\text { CGD2 } \\
\text { ATCC } 43043 \\
(\%)\end{array}$ & $\begin{array}{c}\text { CGD2 } \\
\text { ATCC } 43044 \\
(\%)\end{array}$ & $\begin{array}{c}\text { CGD2 } \\
\mathrm{SCl} \\
(\%)\end{array}$ \\
\hline $\mathrm{C} 14: 1 \Delta 5$ & $7 \cdot 1$ & $6 \cdot 0$ & $7 \cdot 5$ & $2 \cdot 9$ \\
\hline $\mathrm{C} 14: 0$ & $2 \cdot 3$ & $1 \cdot 1$ & 1.0 & 1.5 \\
\hline $\mathrm{C} 15: 0 \mathrm{i}$ & 1.5 & 0.4 & $6 \cdot 3$ & 0.4 \\
\hline $\mathrm{C} 15: 0 \mathrm{a}$ & $0 \cdot 5$ & $0 \cdot 6$ & 0.4 & 0.8 \\
\hline $\mathrm{C} 15: 0 \mathrm{n}$ & $0 \cdot 4$ & 0.4 & $0 \cdot 3$ & $1 \cdot 1$ \\
\hline $\mathrm{C} 16: 1 \Delta 7$ & $8 \cdot 5$ & $7 \cdot 4$ & $6 \cdot 5$ & 3.5 \\
\hline $\mathrm{C} 16: 1 \Delta 9$ & $2 \cdot 8$ & $2 \cdot 3$ & $1 \cdot 6$ & $2 \cdot 1$ \\
\hline $\mathrm{C} 16: 1 \Delta 11$ & $2 \cdot 2$ & $2 \cdot 1$ & $2 \cdot 2$ & 2.9 \\
\hline $\mathrm{C} 16: 0 \mathrm{i}$ & $0 \cdot 1$ & 0.5 & 0.3 & 0.4 \\
\hline $\mathrm{C} 16: 0 \mathrm{n}$ & $16 \cdot 3$ & $16 \cdot 1$ & $15 \cdot 8$ & 16.9 \\
\hline $\mathrm{C17:0 \textrm {i }}$ & 0.5 & 0.5 & 0.7 & 1.4 \\
\hline $\mathrm{C} 17: 0 \mathrm{a}$ & $2 \cdot 2$ & $2 \cdot 8$ & $3 \cdot 1$ & $5 \cdot 7$ \\
\hline $\mathrm{C} 17: 0 \mathrm{n}$ & $0 \cdot 6$ & 0.3 & 0.8 & $1 \cdot 3$ \\
\hline $\mathrm{C} 17: 1 \Delta^{\mathrm{R}_{8}}$ & 0.1 & $0 \cdot 6$ & $0 \cdot 1$ & - \\
\hline $\mathrm{C} 18: 1 \Delta 9^{\circ}$ & $39 \cdot 1$ & $34 \cdot 2$ & 29.9 & $40 \cdot 3$ \\
\hline $\mathrm{C} 18: 0 \mathrm{n}$ & $2 \cdot 5$ & 1.4 & 1.4 & $1 \cdot 3$ \\
\hline $\mathrm{C} 19: 0 \mathrm{R}_{10}$ & 1.6 & $7 \cdot 4$ & $8 \cdot 1$ & $16 \cdot 3$ \\
\hline $\mathrm{C} 19: 1 \Delta^{\mathbf{R}_{10}}$ & $3 \cdot 5$ & $7 \cdot 5$ & $5 \cdot 6$ & - \\
\hline $\mathrm{C} 20: 1 \Delta 11$ & 0.7 & 0.4 & 0.5 & 1.2 \\
\hline $\mathrm{C} 24: 1 \Delta 15$ & $6 \cdot 3$ & $6 \cdot 6$ & $6 \cdot 1$ & - \\
\hline $\mathrm{C} 24: 0 \mathrm{n}$ & $1 \cdot 2$ & 1.4 & 1.8 & - \\
\hline
\end{tabular}



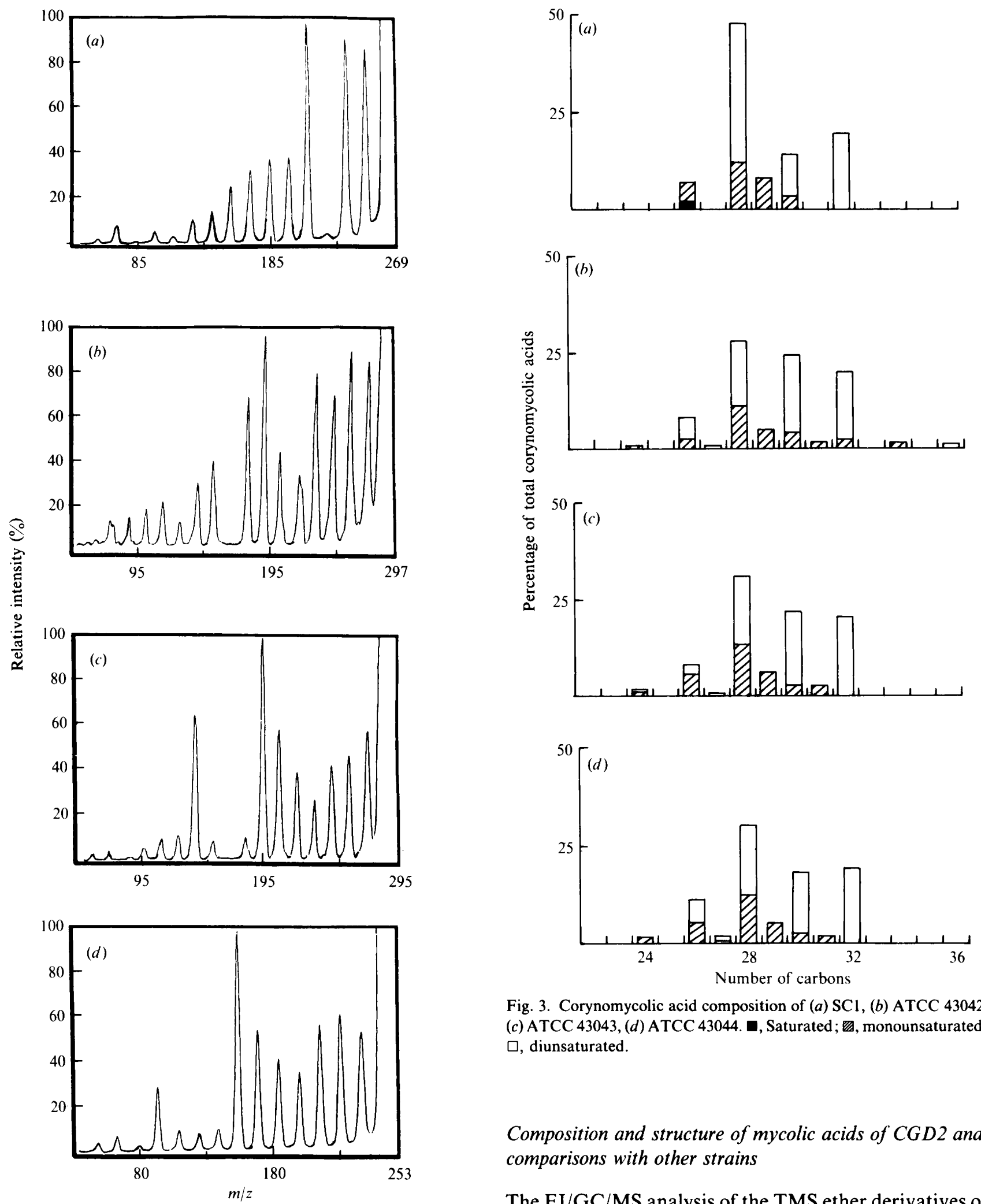

Fig. 3. Corynomycolic acid composition of (a) SCl, (b) ATCC 43042, (c) ATCC 43043, (d) ATCC 43044. E, Saturated; , monounsaturated; $\square$, diunsaturated.

Composition and structure of mycolic acids of CGD2 and comparisons with other strains

The EI/GC/MS analysis of the TMS ether derivatives of the methyl mycolates of the four strains of CGD2 was carried out as described by Yano et al. (1972) and Chevalier et al. (1988). Each species was characterized by the presence of the $(\mathrm{M}-15)^{+}$ion which allowed the acids. The separation of the corresponding PFB derivatives was shown in Fig. 1. (a) C17:0 a (peak $k$ ); (b) C19:0 $\mathrm{R}_{10}$ (peak p); (c) $\mathrm{C} 19: 1 \Delta^{\mathbf{R}}{ }_{10}$ (peak $q$ ); $(d) \mathrm{Cl6}: 1 \Delta 7$ (peak $f$ ). For fatty acid nomenclature, see Table 1. 


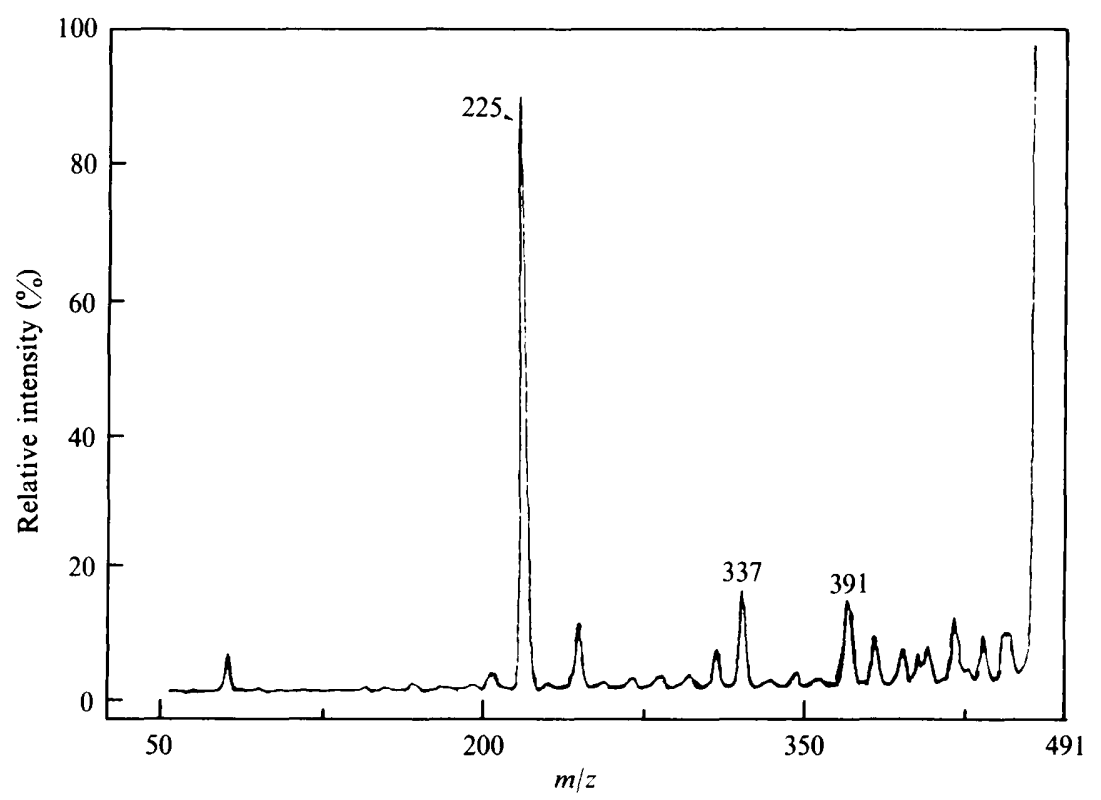

Fig. 4. CAD-MIKE spectrum of the carboxylate anion at $m / z 491$ from the C32 diunsaturated corynomycolic acid (CGD2, strain ATCC 43043).

determination of both total carbon content and the number of double bonds. Fragmentation arising from cleavage of the $\mathrm{C} 2-\mathrm{C} 3$ bond gave the chain length of the alkyl-branch and its degree of unsaturation. Major species corresponded to C32, C30 and C28 diunsaturated mycolic acids. Monounsaturated mycolic acids were less abundant and were observed mainly among the C28 analogues (Fig. 3).

The 2-alkyl branch consisted mainly of a dodecenyl group. The 3-hydroxylated main chain contained either zero or one double bond. Its length ranged from $\mathrm{C} 16$ (C28 mycolic acids) to C20 (C32 mycolic acids).

The position of the double bonds was assigned by negative ion MS/MS (i.e. the charge-remote fragmentation process). Because of the low volatility of PFB ester derivatives of mycolic acids, on-line GC separation was not attempted. Thus, the MS/MS analyses were carried out by direct introduction of these derivatives.

The mycolic acid carboxylate anion MS/MS spectra were dominated by abundant cleavages of the $\mathrm{C} 2-\mathrm{C} 3$ bonds. However, regularly spaced weaker signals due to remote-charge fragmentations were also observed. Examination of the latter allowed the localization of the double bonds. Since both chains were cleaved in parallel, each spectrum was the superimposition of the fragmentation patterns from each chain (Savagnac et al., 1989). The observed spectra from the diunsaturated species were consistent with the exact superimposition of the patterns from the two double bonds, without any shift relative to each other (Fig. 4). This demonstrated that the double bonds were located at the same distance from each methyl end, at the $\omega-9$ position. The same location was observed in the monounsaturated species.

The mycolic acid composition of some medically important corynebacteria is presented in Fig. 5. The comparison of the structure of CGD2 with these corynebacteria (Figs 3 and 5, respectively) revealed both a homogeneous and a specific overall GC pattern for the D2 group.

\section{Discussion}

The fatty acid composition and profile from CGD2, cultivated under conditions different from our own, has been recently described (Soriano et al., 1988; HerreraAlcaraz et al., 1990). However, several components were identified only by comparison with authentic standards. Using capillary GC, coupled with negative ion ionization and MS/MS, we accurately identified all the nonhydroxylated fatty acids. It has been reported (Soriano $e t$ al., 1988) that CGD2 contains both tuberculostearic and tuberculopalmitic acids. We confirmed the presence of the former, but found only traces of the latter. Furthermore, the presence of 10-methylene octadecanoic acid, quantitatively equivalent to tuberculostearic acid, was unexpected in the genus Corynebacterium, since it has previously been detected only in trace amounts, in the genus Mycobacterium. We could only detect trace amounts of tuberculopalmitic acid. However, a relatively 


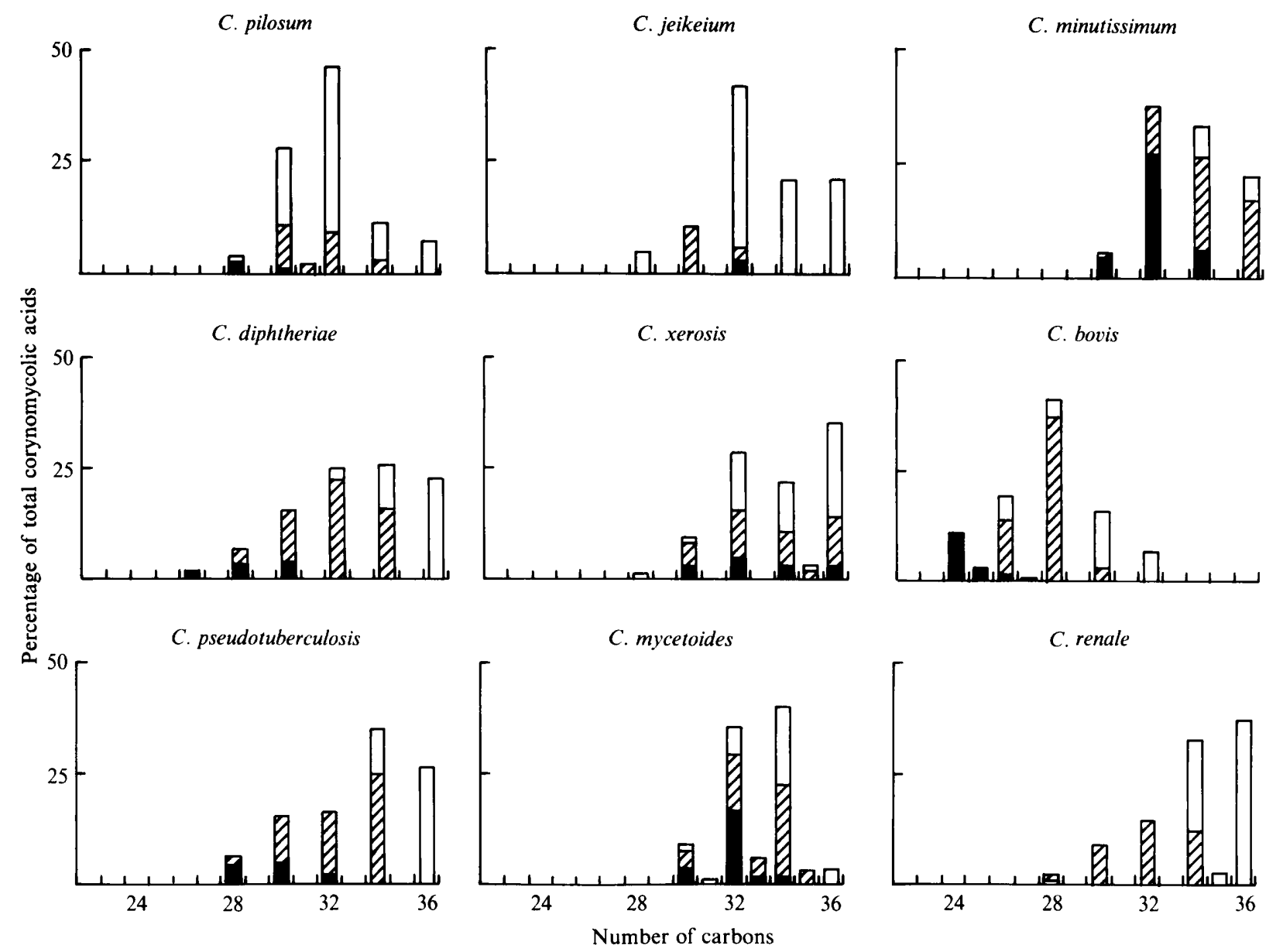

Fig. 5. Comparison of the corynomycolic acid patterns from several coryneform bacteria. $\square$, Saturated; monounsaturated; $\square$, diunsaturated.

large amount of anteiso-heptanoic acid was present among the $\mathrm{C} 17$ branched fatty acids. Moreover, we also observed fatty acids with longer carbon chains, e.g. $\Delta 15$-tetracosenoic acid, which is an unusual feature in corynebacteria. Most of the straight chain unsaturated fatty acids detected belong to the $\omega-9$ series. The exception was the $\mathrm{C} 16: 1$ species in which small amounts of $\omega-5$ and $\omega-7$ unsaturated fatty acids were also present. The presence of many unsaturated fatty acids from the $\omega-9$ series may be consistent with their biosynthesis via an anaerobic-like pathway involving the elongation of a cis $\Delta 3$-dodecenoic acid, as proposed for several coryneform bacteria (Suzuki et al., 1982). However, it has been reported that several Corynebacterium strains were able both to hydrolyse Tween 80 , used to supplement the culture medium, and to use its oleic acid part for the synthesis of fatty acids (Chevalier et al., 1988). Thus, the origin of $\omega-9$ unsaturated fatty acids from the CGD2 stains may be due to elongation or shortening of oleic acid from Tween 80 .
Structures of mycolic acids from coryneform bacteria have received a great deal of attention and have been used as a tool for the identification of medically important strains (Yano et al., 1972; Minnikin et al., 1978; Athalye et al., 1984, 1985). It has been shown that corynebacteria can take up fatty acids from the culture medium, and that its composition can influence the nature of the mycolic acids synthesized (Chevalier et al., 1988). Thus, all comparisons between different strains of corynebacteria must be under standardized cultivation conditions. Hence, we examined several coryneform strains grown on the same medium supplemented with Tween 80. The mycolic acids from the four CGD2 strains exhibited very similar compositions, but their pattern was different from all other coryneform strains. Particularly, a distinction from Corynebacterium jeikeium could be achieved by examination of the mycolic acid composition. It was notable that the mycolic acid composition of CGD2 we observed was clearly different from that recently described by Herrera-Alcaraz et al. 
(1990), particularly regarding the number of double bonds. This is probably due to different culture conditions. Nevertheless, provided identical growth conditions are used for all strains, the mycolic acid pattern seems a convenient tool for the identification of coryneforms including Corynebacterium D2.

This research was supported by the Institute of Bacteriology in Strasbourg (Pr Minck). The authors wish to thank Dr R. E. Weaver, Centers for Disease Control, Atlanta, for the confirmation of the identification of the $\beta$-lactam-susceptible strain of Corynebacterium D2.

\section{References}

AdAMS, J. (1990). Charge remote fragmentation: analytical applications and fundamental studies. Mass Spectrometry Reviews 9, 141-186.

Akamatsu, Y. \& Law, J. H. (1970). Enzymatic alkylenation of phospholipid fatty acid chains by extracts of Mycobacterium phlei. Journal of Biological Chemistry 245, 701-708.

Athalye, M., Noble, W. C., Mallet, A. I. \& Minnikin, D. E. (1984). Gas chromatography-mass spectrometry of mycolic acids as a tool in the identification of medically important coryneform bacteria. Journal of General Microbiology 130, 513-519.

Athalye, M., Noble, W. C. \& Minnikin, D. E. (1985). Analysis of cellular fatty acids by gas chromatography as a tool in the identification of medically important coryneform bacteria. Journal of Applied Bacteriology 58, 507-512.

Chevalier, J., Pommier, M. T., Crémieux, A. \& Michel, G. (1988). Influence of Tween 80 on the mycolic acid composition of three cutaneous corynebacteria. Journal of General Microbiology 134, 2457-2461.

Collins, M. D., Goodfellow, M. \& Minnikin, D. E. (1982). A survey of the structures of mycolic acids in Corynebacterium and related taxa. Journal of General Microbiology 128, 129-149.

Corina, D. L. \& SeSARDIC, D. (1980). Profile analysis of total mycolic acids from skin corynebacteria and from named Corynebacterium strains by gas-liquid chromatography and gas-liquid chromatography/mass spectrometry. Journal of General Microbiology 116, $61-68$.

Couderc, F., Aurelle, H., Promé, D., Savagnac, A. \& Promé, J. C. $(1989 a)$. Analysis of fatty acids by negative ion gas chromatography/tandem mass spectrometry: structural correlations between $\alpha$-mycolic acid chains and $\Delta 5$-monounsaturated fatty acids from Mycobacterium phlei. Biomedical and Environmental Mass Spectrometry 16, 317-321.

Couderc, F., Roche, P., Raynaud, C., Pougny, J. R. \& Promé, J. C. $(1989 b)$. Characterization of fatty acids with a methyl branch near to a double bond by MS/MS analysis of their carboxylate anions. Advances in Mass Spectrometry 11B, 1496-1497.

Courcelle, E., Pratbernou, F. \& Promé, J. C. (1989). A simple mass spectrometry data system dedicated to fast atom bombardment mass spectrometry. Review of Scientific Instruments 60, 3181-3187.

Daffé, M., Lanéelle, M. A., Asselineau, C., Lévy-Frébault, V. \& DAVID, H. (1983). Intérêt taxonomique des acides gras de mycobacteries: proposition d'une méthode d'analyse. Annales de Microbiologie (Institut Pasteur) 134B, 241-256.
De Briel, D., Langs, J. C., Rougeron, G., Chabot, P. \& Le Faou, A. (1991). Multiresistant corynebacteria in bacteriuria: a comparative study of the role of Corynebacterium group D2 and Corynebacterium jeikeium. Journal of Hospital Infection 17A, 35-43.

Herrera-Alcaraz, E. A., Valero-Guillén, P. L., Martin-Luengo, F. \& Soriano, F. (1990). Taxonomic implications of the chemical analysis of the D2 group of corynebacteria. FEMS Microbiology Letters 72, 341-344.

JONES, D. \& Collins, M. D. (1986). Irregular, non-sporing Grampositive rods. In Bergey's Manual of Systematic Bacteriology, Vol. 2, pp. 1261-1434. Edited by P. H. A. Sneath, N. S. Mair, M. E. Q. Sharpe \& J. G. Holt. Baltimore: Williams \& Wilkins.

KING, E. O. (1972). The identification of unusual Gram-negative bacteria (preliminary revision, September 1972). Edited by E. Weaver, H. W. Tatum \& D. G. Hollis. Atlanta Centers for Disease Control.

Langs, J. C., De Briel, D., Sauvage, C., Bliklé, J. F. \& Akel, H. (1988). Endocardite à Corynebacterium du groupe D2 à point de départ urinaire. Médecine et Maladies Infectieuses 5, 293-295.

LeNFANT, M., Audier, H. \& LeDERER, E. (1966). Sur une migration d'hydrogène au cours de la biosynthèse de l'acide tuberculostéarique. Bulletin de la Société Chimique de France 9, 2775-2777.

Minnikin, D. E., Goodfellow, M. \& Collins, M. D. (1978). Lipid composition in the classification and identification of coryneform and related taxa. In Coryneform Bacteria, pp. 85-160. Edited by I. J. Bousfield \& A. G. Callely. London: Academic Press.

MinNikin, D. E. \& Goodfellow, M. (1980). Lipid composition in the classification and identification of acid-fast bacteria. In Microbiological Classification and Identification, pp. 189-256. Edited by M. Goodfellow \& R. G. Board. London: Academic Press.

Promé, J. C., Aurelle, H., Casas, C., Couderc, F., Savagnac, A. (1987). Structural determination of unsaturated fatty acids in complex mixtures by capillary GC/MS-MS. Rapid Communication in Mass Spectrometry 1, 50-52.

Promé, J. C., Aurelle, H., Couderc, F., Promé, D., Savagnac, A. \& Treilhou, M. (1990). Structural determination of unsaturated long chain fatty acids from Mycobacteria by capillary gas chromatography and collision activation dissociation mass spectrometry. In Analytical Microbiology Methods. Edited by A. Fox, S. L. Morgan, L. Larsson \& G. Odham. New York: Plenum Press.

Savagnac, A., Aurelle, H., Casas, C., Couderc, F., Gavard, P., Promé, D. \& Promé, J. C. (1989). Structure determination of mycolic acids by using charge remote fragmentation. Chemistry and Physics of Lipids 51, 31-38.

Soriano, F. \& Fernandez-Roblas, R. (1988). Infections caused by antibiotics-resistant Corynebacterium group D2. European Journal of Clinical Microbiology 7, 337-341.

Soriano, F., Martin-Luengo, F., Valero, P. L., Santamaria, M. \& FERNANDEZ-RoBlas, R. (1988). Caracterizaciòn e identificaciòn de Corynebacterium grupo D2 aislados de muestras clinicas. Enfermedades Infecciosas y Microbiologeà Clinica 6, 235-238.

SuzuKI, K. I. \& Komagata, K. (1983). Taxonomic significance of cellular fatty acid composition in some coryneform bacteria. International Journal of Systematic Bacteriology 33, 188-200.

Suzuki, K. I., Kawaguchi, A., Saito, K., Okuda, S. \& Komagata, K. (1982). Taxonomic significance of the position of double bonds of unsaturated fatty acids in corynebacteria. Journal of Applied Microbiology 28, 409-416.

TOMER, K. B., Crow, F. W. \& Gross, M. L. (1983). Location of double bond position in unsaturated fatty acids by negative ion MS/MS. Journal of the American Chemical Society 105, 5487-5488.

Yano, I., Saito, K., Furukawa, Y. \& Kusunose, M. (1972). Structural analysis of molecular species of nocardomycolic acids from Nocardia erythropolis by combined system of gas chromatography and mass spectrometry. FEBS Letters 21, 215-219. 